\title{
A Rare Case of Pseudoaneurysm and an Arteriovenous Fistula of the Lumbar Artery Treated by Endovascular Intervention
}

\author{
Le Viet Dung ${ }^{1}$, Nguyen Minh Duc ${ }^{2,3,4},{ }^{*}$, Thieu-Thi Tra My ${ }^{1}$, Doan Tien Luu ${ }^{1,2}$, Le Tuan Linh ${ }^{1,2}$, Thai Khac Chau ${ }^{5}$
}

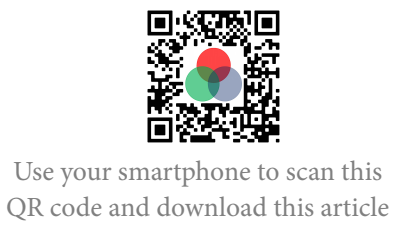

${ }^{1}$ Department of Radiology, $\mathrm{Ha} \mathrm{Noi}$ Medical University Hospital, Ha Noi, Viet Nam

${ }^{2}$ Department of Radiology, $\mathrm{Ha}$ Noi Medical University, Ha Noi, Viet Nam

${ }^{3}$ Department of Radiology, Pham Ngoc Thach University of Medicine, Ho Chi Minh City, Viet Nam

${ }^{4}$ Department of Radiology, Children's Hospital 2, Ho Chi Minh City, Viet Nam

${ }^{5}$ Department of Radiology, Vietnam Military Medical University, Ha Noi, Viet Nam

\section{Correspondence}

Nguyen Minh Duc, Department of Radiology, Ha Noi Medical University, Ha Noi, Viet Nam

Department of Radiology, Pham Ngoc Thach University of Medicine, Ho Chi Minh City, Viet Nam

Department of Radiology, Children's Hospital 2, Ho Chi Minh City, Viet Nam Email: bsnguyenminhduc@pnt.edu.vn History

- Received: Nov 08, 2021

- Accepted: Dec 15, 2021

- Published: Dec 31, 2021

DOI : 10.15419/bmrat.v8i12.716

\section{Check for updates}

\section{Copyright}

(๑) Biomedpress. This is an openaccess article distributed under the terms of the Creative Commons Attribution 4.0 International license.

\begin{abstract}
Traumatic lumbar artery injuries are quite uncommon, and arteriovenous fistula (AVF) lesions are also rare. The clinical symptoms associated with AVF of the lumbar artery are often vague and non-specific and can be masked by symptoms due to the spinal cord injury. Therefore, AVF of the lumbar artery can often be missed if the performance of a contrast-enhanced computed tomography (CECT) scan is absent. In this article, we portrait a case of post-traumatic lumbar artery AVF along with pseudoaneurysm in a 40-year-old who suffered from pain in the right lumbar region. After endovascular intervention therapy for one month, the Visual Analogue Scale (VAS) was 1 in comparison with 8 prior to treatment. Thus, an endovascular intervention should be considered an effective treatment option for AVF and pseudoaneurysm of the LA.
\end{abstract}

Key words: Arteriovenous fistula, Embolization, Lumbar artery, Pseudoaneurysm

\section{INTRODUCTION}

Injury to the lumbar artery (LA) can occasionally lead to life-threatening retroperitoneal hemorrhage ${ }^{1}$. The two most common types of LA lesions are pseudoaneurysms and active bleeding ${ }^{2}$. Arteriovenous fistula (AVF) lesions are extremely rare, although some reports indicate that AVF represents a late complication caused by the erosion and rupture of a pseudoaneurysm into adjacent veins, such as the inferior vena cava (IVC) or the iliac veins. However, the formation of an AVF may also be categorized as an acute onset $^{3-5}$. The complications associated with these types of injuries include a rupture into the retroperitoneal space, causing acute blood loss, and heart failure due to the increased preload by the arteriovenous flow 5 . Here, we present a clinical case of pseudoaneurysm with AVF of the LA that was successfully embolized.

\section{CASE PRESENTATION}

This case report was complied in accordance with the Declaration of Helsinki. Appropriate informed consent for the patient information to be published in this article was obtained.

A 40-year-old male patient was involved in a traffic accident 2 years ago and was diagnosed with a cauda equina injury, burst fracture, and unstable L4 vertebrae without abdominal organ trauma. The patient underwent surgery to fix their spine, during which the vertebral bodies L2, L3, L5, and S1 were attached through the pedicle using screws. The surgery had a favorable outcome, and the patient was stable after surgery. The patient did not undergo contrastenhanced computed tomography (CECT) before or after surgery. Two years after the surgery, the patient experienced pain in the right lumbar region with a VAS of 8 that lasted for one month. CECT showed a large pseudoaneurysm of the right L4 LA and communication with the nearby IVC (Figure 1). Angiography and embolization were indicated to achieve a clearer diagnosis and determine optimal treatment. Upon conducting a digital subtraction angiography (DSA), the lesion was clearly shown to be a pseudoaneurysm of the L4 LA, sized approximately 60 $\mathrm{mm} \times 40 \mathrm{~mm}$, with a fistula connecting to the IVC (Figure 2). The patient underwent embolization to treat the lesions. An Introducer 6F (Teruma, Japan) catheter was placed in the right femoral artery, and a Chaperon 6F catheter (Microvention, USA), an Impress 5F (Merit Medical, USA) catheter, and a $2.7 \mathrm{~F}$ Corsair microcatheter (Asahi, Japan) were inserted to approach the lesion. We released a 10-mm Amplatzer Vascular Plug (AVP; AGA, USA) with one Penumbra soft complex coil, $6 \mathrm{~mm} \times 20 \mathrm{~cm}$ (Penumbra, USA) using controlled deployment (Figure 3). DSA was performed again to verify the plug placement, revealing a minor fistula. We proceeded to place an additional Cirrus $4 \times 50 \mathrm{~mm}$ coil (Balt, France) through pushed deployment. The endovascular intervention therapy was successful since the final DSA image showed the complete occlusion of the pseudoaneurysm and fistula (Figure 4). The patient was discharged 2-days post-treatment without any adverse Intervention. Biomed. Res. Ther., 2021; 8(12):4803-4808. 


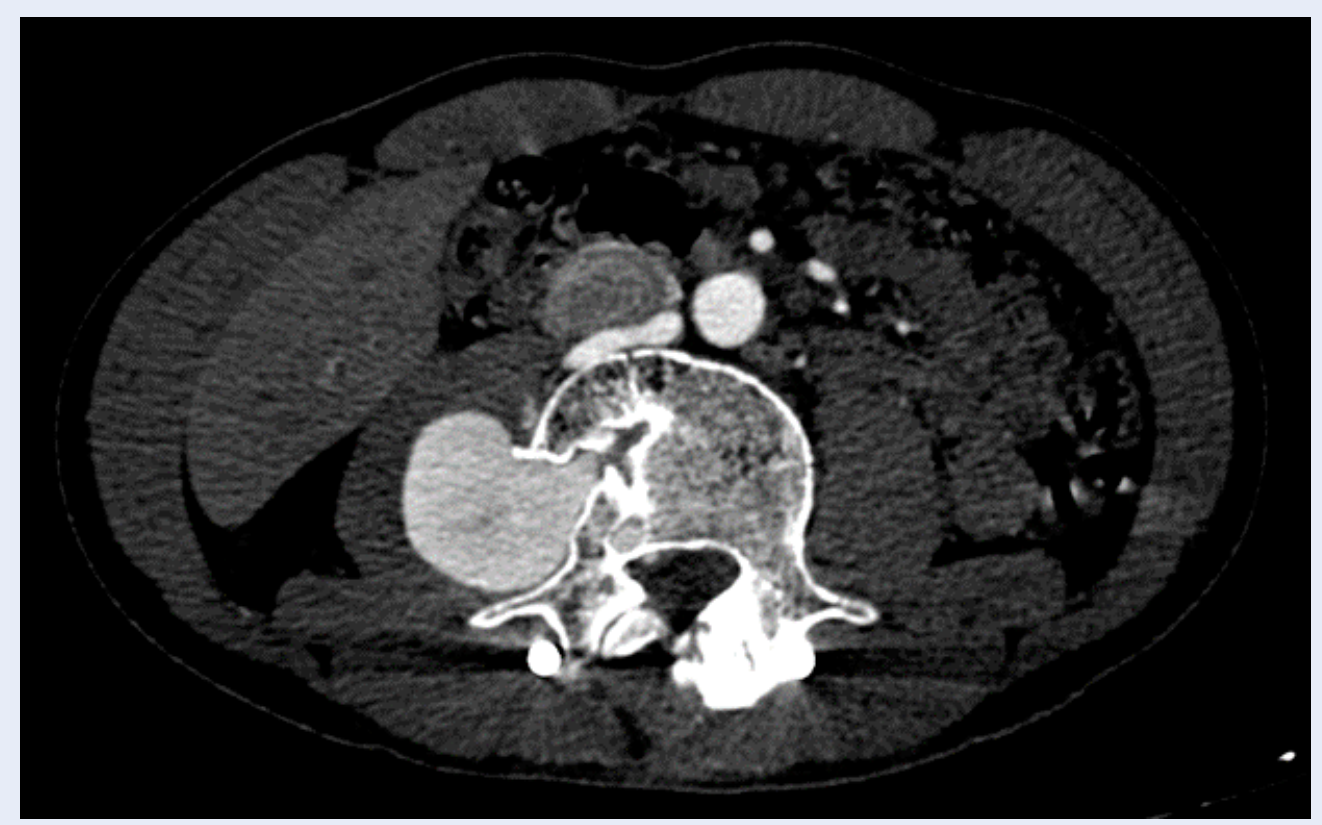

Figure 1: Contrast-enhanced computed tomography (CECT) arterial phase showing a pseudoaneurysm and arteriovenous fistula (AVF) of the right L4 lumbar artery (LA; double arrow).

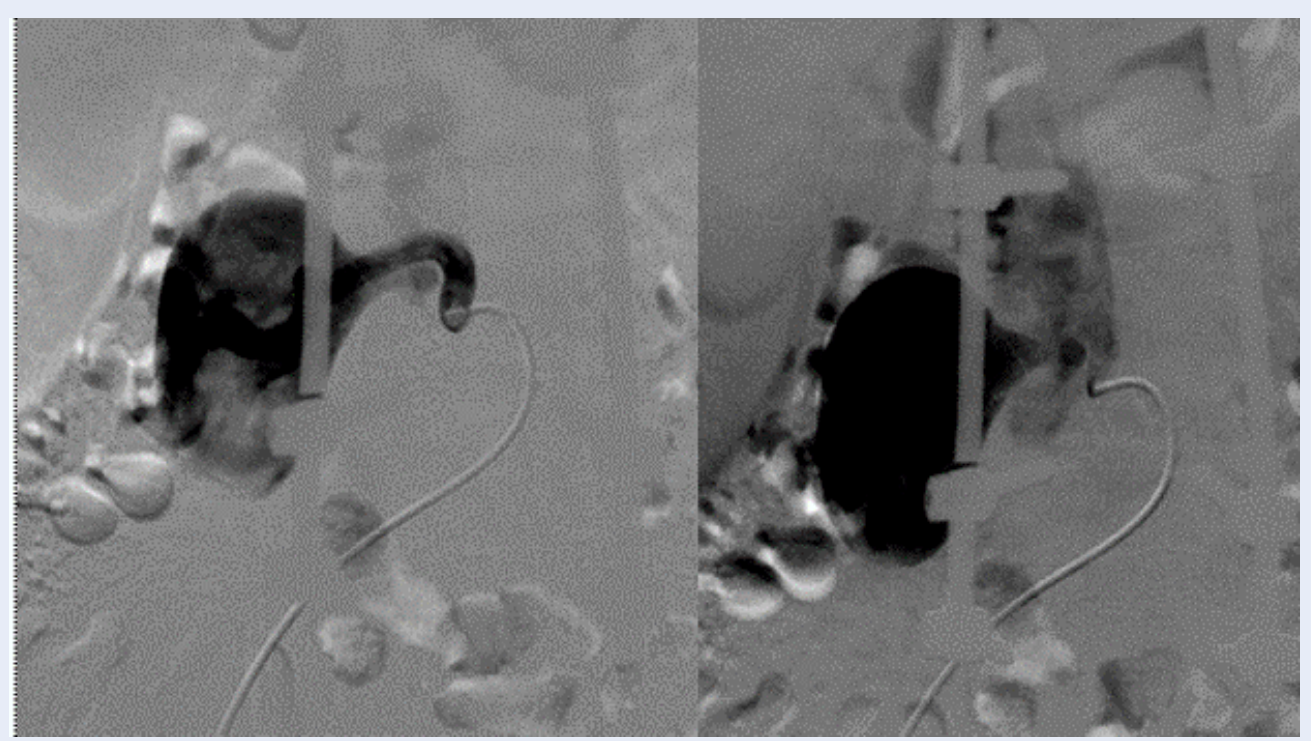

Figure 2: Digital subtraction angiography (DSA) of right L4 lumbarartery (LA). Left: pseudoaneurysm (arrow). Right: arteriovenous fistula (AVF, arrow). 
events. One-month post-treatment, the VAS was 1 with a reduction rate of $87.5 \%$.

\section{DISCUSSION}

The LAs originate from the posterior lateral border of the abdominal aorta ${ }^{6}$, typically presenting as 4 pairs of LAs ${ }^{6}$. The most common anatomical variation occurs in the right and left common trunk arteries ${ }^{6}$. Less common variants are the appearance of a fifth pair of LAs derived from the median sacral artery and the presence of only 3 pairs of LAs from L1 to L3 ${ }^{6}$. The LAs feature multiple anastomoses and are continuous with the posterior intercostal arteries, the lumbar-iliac arteries, and the inferior epigastric arteries $^{6}$. Between the LAs and the presence of the abdominal aortic vessels, the retroperitoneal space represents a rich vascular space, making some surgeons reluctant to operate in this region ${ }^{5}$. Branches from the LA supply blood to the muscles, dorsal fascia, and the vertebral bodies and disks ${ }^{6}$. In some cases, the blood supply may branch to the spinal cord ${ }^{2}$. Due to the existence of many intersecting connections, angiography should be used to verify all LAs, even after embolization.

Injury to the LA can occur due to abdominal trauma or abdominal-back injuries (such as shooting or stabbing) ${ }^{1}$. Vascular injury to the LA has also been reported as a complication of spinal surgery, percutaneous lithotripsy, and even splenectomy ${ }^{4,5,7}$. The most common lesion pattern is pseudoaneurysm and active bleeding ${ }^{2}$. Although the LA is not a large artery and the retroperitoneal space is relatively narrow, bleeding from the LA can result in relatively large blood loss, followed by clinical hypovolemic shock ${ }^{\mathbf{1 , 5}}$. Sclafani reported on 12 patients with traumatic injury of the LA including 10 patients who were in shock when they arrived in the emergency room; 11 patients had spinal trauma, including 10 cases of vertebral body fractures ${ }^{8}$. Among these 12 patients, 3 patients presented with active bleeding, and the remaining patients were diagnosed with pseudoaneurysms of the LA, accounting for a total of 25 injured LAs, all at the level of the fractured vertebra, especially at the level of L3 and $\mathrm{L} 4{ }^{8}$. Sofocleous, in a study of visceral vascular lesions associated with trauma over a 10-year period from 1991 to 2001, reported 11 patients with LA injury, including a total of 15 affected LAs, comprising 4 pseudoaneurysms and 11 with active bleeding $^{2}$. The authors employed coil embolization in 6 patients, 4 patients received Gelfoam, and 1 case received a combination of particles and Gelfoam ${ }^{2}$. In addition, 1 case embolized with Gelfoam presented with rebleeding after 4 days, although no late complications were recorded ${ }^{2}$. Papadouglas, in a retrospective literature review, described vascular injury complications associated with lumbar disk surgery, reporting a total of 99 cases which included injury to the LA, aorta, IVC, and iliac vessels ${ }^{5}$.

AVF lesions of the LA are extremely rare ${ }^{4}$. Maleux, in his article in 2002, described 1 case of pseudoaneurysm with AVF of the LA resulting in the formation of a direct fistula from the LA to a nearby lumbar vein $^{4}$. This clinical case was a complication associated with a laparoscopic splenectomy, and the patient underwent successful endovascular intervention ${ }^{4}$. The authors first attempted coil embolization but upon identifying the continued flow, opted for combination therapy using Histoacryl ${ }^{4}$. In cases with an AVF diagnosis, due to the damage to the vessel wall, acute lesions often develop retroperitoneal hematomas which affect the hemodynamic parameters ${ }^{9}$. With chronic insidious AVF, the clinical presentation can often be non-specific, most commonly dyspnea on exertion due to increased cardiac output or heart failure ${ }^{9}$. On CECT, venous drainage can be observed early in the arterial phase, in some cases with associated pseudoaneurysm ${ }^{9}$. DSA is the gold standard for the diagnosis of AVF and it can be used to guide the treatment strategy. The differential diagnosis for arteriovenous malformations includes enlarged feeding arteries and nidus. In our case, the lesion morphology was clearly diagnosed as a pseudoaneurysm with AVF between the LA and IVC. However, the mechanism of injury remains controversial. Because the injured artery was located near the traumatized vertebral body, far from the screws, the vessel damage was likely caused by the initial trauma rather than the spinal surgery.

Treatment options for AVF of the LA primarily include surgery and endovascular interventions ${ }^{1}$. If the lesion is detected intraoperatively or as a complication of surgery that is diagnosed intraoperatively, vascular ligation and the suturing of large vessels are commonly performed ${ }^{5}$. LAs are difficult to control operatively as both the anterior and posterior surgical approaches place the ureter and lumbar plexus at risk $^{2}$. If no other lesions are identified that necessitate surgery or the disease is chronically progressive, endovascular intervention is often preferred ${ }^{4,10}$. The embolization of the LA has been shown to be safe in many reports. Many blood supplies and arterial anastomoses feed the muscles and fascia of these regions $^{\mathbf{1}, 4,10}$. However, careful evaluation should be performed when a spinal feeding branch is treated. Early intervention should be initiated because longterm exposure increases the cardiac preload and pseudoaneurysms (as in our case) can rupture, causing 


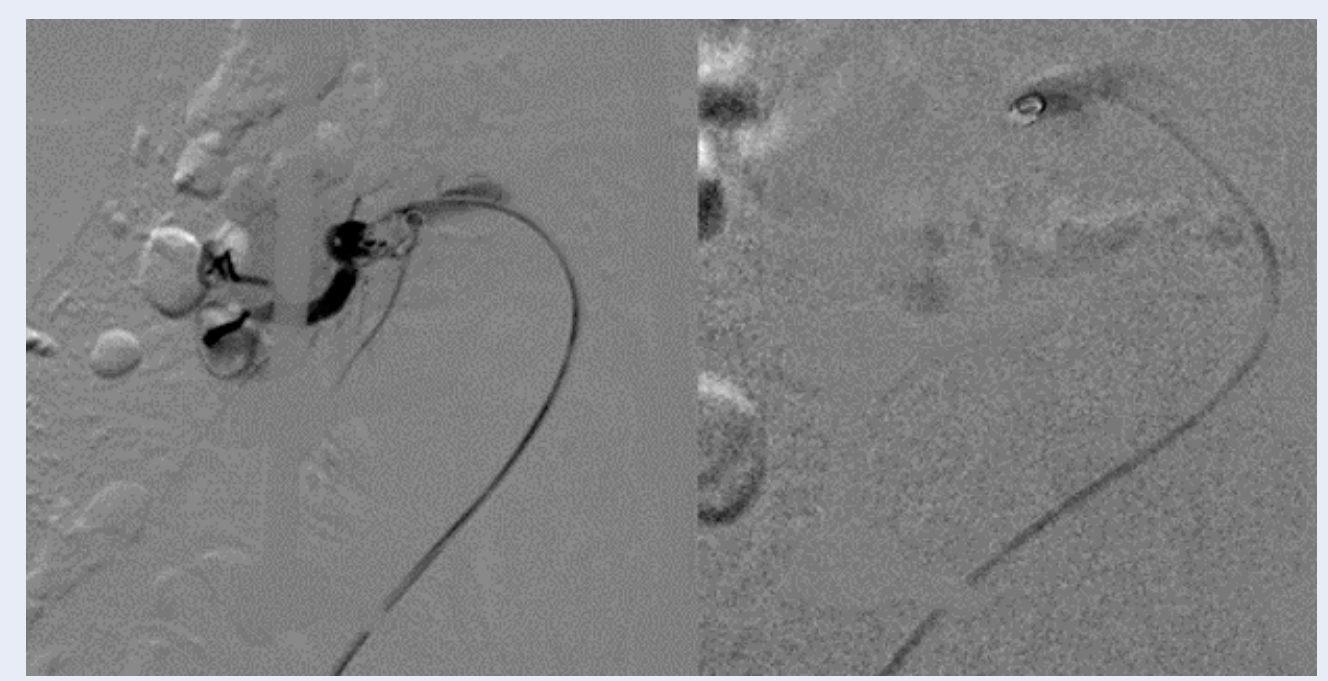

Figure 3: Digital subtraction angiography (DSA) intervention. Left: The placement of a 10-mm AVP and a Penumbra sized $6 \mathrm{~mm} \times 20 \mathrm{~cm}$ (arrow). Right: Follow-up with a 1 coil Penumbra $6 \mathrm{~mm} \times 20 \mathrm{~cm}$ (arrow).

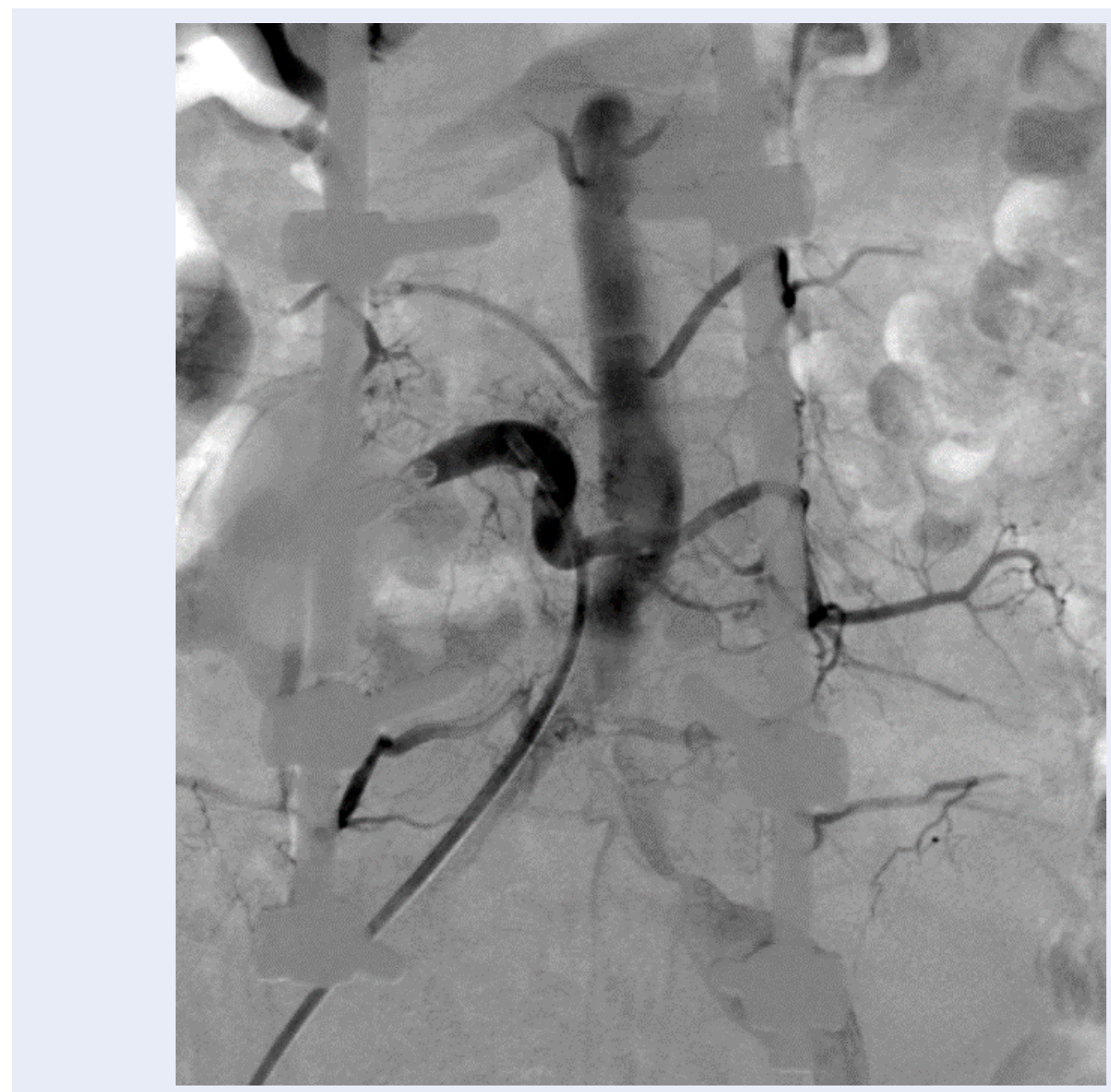

Figure 4: Digital subtraction angiography (DSA) of the right L4 lumbar artery (LA) after embolization, showing the total occlusion of the lesion (arrow). 
acute blood loss that can place the patient's life at risk $^{1,2}$. Interventional materials used to treat pseudoaneurysm and active bleeding include Histoacryl or coils. Gelfoam may be used for concealed lesions ${ }^{2}$. However, with a large AVF as observed in our case, Histoacryl, particles, or Gelfoam materials can migrate. Therefore, the most suitable materials are plugs coordinated with coils. One important consideration is cost as AVP is cheaper than coils, and large AVFs often require multiple coils. With large AVFs, some studies have reported the dual use of an Amplatzer Device $^{11}$. With a large fistula as in our case, using coils first is associated with the risk of coil migration. Therefore, we opted to use an AVP first followed by coils which resulted in total lesion occlusion. In our case, one-month post-treatment, the main symptom was resolved completely without any complications. In comparison with conventional approaches, an endovascular intervention seems to have more advantages including no blood loss, a low rate of adverse events, faster recovery time, and short hospital stay. Our results were found to be fully in agreement with the prior reports that emphasized endovascular intervention as an efficacious therapy for AVF of LA ${ }^{\mathbf{1 , 4 , 1 0}}$.

\section{CONCLUSION}

To summarize, our case confirmed that pseudoaneurysm and AVF of the LA after trauma is rare in clinical practice. The clinical presentation of this occurrence tends to be non-specific like pain in the lumbar region. CECT is the primary diagnostic approach for LA injury. In this circumstance, endovascular interventions have many advantages such as a low complication rate, no blood loss, quick recovery time, and short hospital stay over conventional surgery for the treatment of AVF of the LA. We recommend that an early intervention is necessary to avoid complications including heart failure due to the large flow and to prevent pseudoaneurysm rupture, which can result in massive acute blood loss.

\section{ABBREVIATIONS}

AVF: Arteriovenous fistula, CECT: Contrastenhanced computed tomography, DSA: Digital subtraction angiography, LA: Lumbar artery, VAS: Visual Analogue Scale

\section{ACKNOWLEDGMENTS}

This article was derived from a research project approved by the Esfarayen University of Medical Sciences, which was conducted with the financial support of this university. The researchers would like to express their gratitude to the University Research Council and all patients, who participated in this study.

\section{AUTHOR'S CONTRIBUTIONS}

Le VD and Nguyen MD contributed equally to this article as co-first authors. All authors significantly contributed to the conceptualization and design of the study, the acquisition, analysis and interpretation of data. All authors read and approved final version of this manuscript.

\section{FUNDING}

None.

\section{AVAILABILITY OF DATA AND MATERIALS}

Data sharing is not applicable to this article as no datasets were generated or analysed during the current study.

\section{ETHICS APPROVAL AND CONSENT TO PARTICIPATE}

Appropriate informed consent for patient information to be published in this article was obtained. Our institution does not require ethical approval for reporting individual cases or case series.

\section{CONSENT FOR PUBLICATION}

Not applicable.

\section{COMPETING INTERESTS}

The authors declare that they have no competing interests.

\section{REFERENCES}

1. Chan KT, Korivi N. Lumbar artery pseudoaneurysm in traumatic spinal cord injury: a case report. Archives of Physical Medicine and Rehabilitation. 2003;84(3):455-7. PMID: 12638116. Available from: 10.1053/apmr.2003.50029.

2. Sofocleous CT, Hinrichs CR, Hubbi B, Doddakashi $S$, Bahramipour $\mathrm{P}$, Schubert J. Embolization of isolated lumbar artery injuries in trauma patients. Cardiovascular and Interventional Radiology. 2005;28(6):730-5. PMID: 16184334. Available from: 10.1007/s00270-003-0117-7.

3. Franzini M, Altana P, Annessi V, Lodini V. latrogenic vascular injuries following lumbar disc surgery. Case report and review of the literature. The Journal of Cardiovascular Surgery. 1987;28(6):727-30. PMID: 3667685.

4. Maleux G, Vermylen J, Wilms G. Lumbar artery pseudoaneurysm and arteriovenous fistula as a complication of laparoscopic splenectomy: treatment by transcatheter embolization. European Radiology. 2002;12(6):1401-4. PMID: 12042945. Available from: 10.1007/s00330-001-1175-3.

5. Papadoulas S, Konstantinou D, Kourea HP, Kritikos N, Haftouras N, Tsolakis JA. Vascular injury complicating lumbar disc surgery. A systematic review. European Journal of Vascular and Endovascular Surgery. 2002;24(3):189-95. PMID: 12217278. Available from: 10.1053/ejvs.2002.1682. 
6. Karunanayake AL, Pathmeswaran A. Anatomical variations of lumbar arteries and their clinical implications: a cadaveric study. ISRN Anatomy. 2013;2013:154625. PMID: 25938093. Available from: 10.5402/2013/154625.

7. Santillan A, Patsalides A, Gobin YP. Endovascular embolization of iatrogenic lumbar artery pseudoaneurysm following extreme lateral interbody fusion (XLIF). Vascular and Endovascular Surgery. 2010;44(7):601-3. PMID: 20675335. Available from: $10.1177 / 1538574410374655$.

8. Sclafani SJ, Florence LO, Phillips TF, Scalea TM, Glanz S, Goldstein AS. Lumbar arterial injury: radiologic diagnosis and management. Radiology. 1987;165(3):709-14. PMID: 3685349. Available from: 10.1148/radiology.165.3.3685349.

9. Chou CP, Pan HB, Wu TH, Huang FD, Wu MT. Traumatic lumbar artery arteriovenous fistula: preclinically detected by 16-multidetector-row computed tomography and postprocessing techniques. Acta Radiologica (Stockholm, Sweden). 2007;48(4):401-4. PMID: 17453520. Available from: 10.1080/02841850701199926.

10. Jain R, Kumar S, Phadke RV, Baijal SS, Gujral RB. Intraarterial embolization of lumbar artery pseudoaneurysm following percutaneous nephrolithotomy. Australasian Radiology. 2001;45(3):383-6. PMID: 11531772. Available from: 10.1046/j.1440-1673.2001.00880.x.

11. Idowu O, Barodawala F, Nemeth A, Trerotola SO. Dual use of an amplatzer device in the transcatheter embolization of a large high-flow renal arteriovenous fistula. Journal of Vascular and Interventional Radiology. 2007;18(5):671-6. PMID: 17494851. Available from: 10.1016/j.jvir.2007.02.008. 
Ready to submit your manuscript? Choose Biomedpress and benefit from:

- Fast, convenient online submission

- Through peer-review by experienced researchers

- Rapid publication on acceptance

- Free of charge (without publication fees)

Learn more http://www.biomedpress.org/journals/
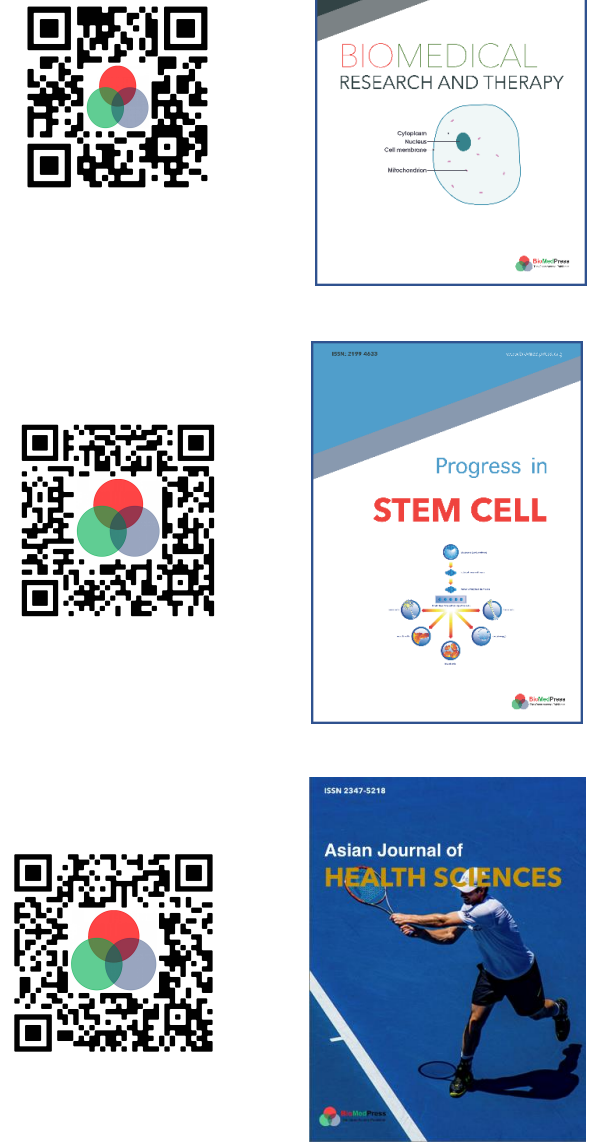

Asian Journal of Health Sciences

ISSN: 2347-5218

Indexed: Google Scholar

Acceptance Rate (2020): 72.89\%

Article Publishing Charge: Free

Submission to first editorial decision: 16.5 days

Biotechnological Research

ISSN: 2395-6763

Indexed: Google Scholar

Acceptance Rate (2020): $67.02 \%$

Article Publishing Charge: Free

Submission to first editorial decision: 28.5 days 